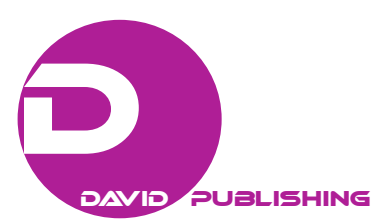

\title{
Insurance Sales Marketing
}

\author{
Alexander Fichter \\ Universzita Komenskeho v Bratislave, Bratislava, Slovenska Republika
}

\begin{abstract}
The aim of the work is to research insurance sales for the future. The new technologies and media will also change distribution. The method was field research through our own customer base. Questionnaires from interviews were used and evaluated. Numerous insights have been gained from customer behaviour and which can also be transferred to other industries. These findings require that customer communication be changed at all sales levels. Every customer contact has an impact on consumption, so an adjustment is necessary. The main objective has been achieved and the work can serve the whole insurance industry. Furthermore, transferability to other industries is possible.
\end{abstract}

Keywords: digital distribution, future sales, sales model

\section{Introduction}

Insurance distribution is facing the biggest changes of the last decades. These are triggered by numerous factors with profound consequences:

Change in customer expectations due to experiences from other areas of life;

Technological progress, which offers new opportunities but also increases the requirements for process efficiency of insurers;

New digital competitors who are stepping up the fight for access to customers;

Demographic changes: The world is getting older and more urban;

Increasing regulation requiring more transparency and process security;

Omnipresent cost pressure, which will result in a drastic reduction in commission volume and comprehensive reduction in sales overhead costs.

Together, these factors unfold an explosive effect that has to be defused by reorganizing the sales models.

All models rely on offering tailor-made "customer journeys"- the various contact points of a potential customer with the insurance at different points in the sales process - and offer digitally supported, frictionless and cost-efficient processes" (Sommer, 1996, p. 5). However, the fundamental question changes in the design of the sales strategy: Although most insurers are aware of the changes that are needed, effective change is often hampered by a variety of hurdles, such as the complexity of the distribution model, inadequate IT expertise, and legitimate fear of losing business.

Especially against the background of these hurdles, the necessary process of change takes time. Insurers must therefore start today to work out a new strategic direction and initiate the necessary transformation

Alexander Fichter, M.A., Ph.D. student, Fakulta Managementu, Universzita Komenskeho v Bratislave, Bratislava, Slovenska Republika.

Correspondence concerning this article should be addressed to Alexander Fichter, Fakulta Managementu, Universzita Komenskeho v Bratislave, 82005 Bratislava 25, Odbojarov 10, Slovenska Republika. 
process. Otherwise, they run the risk of missing out on the current strategic window of change (Browne \& Kim, 1993, S. 7).

\section{Change of the Insurance Sales in the Future}

Insurance distribution is facing the biggest changes of the last decades, which are determined by six major drivers of change:

- Customer expectations: These are changing radically, sustainably, and quickly. Customers expect that they will always have all the interaction options to deal with insurers as they are used to in other areas of life. Self-determination, transparency, personalization, simplicity speed, and a smooth transition from online to offline are required 24 hours/7 days a week.

- Technology: Insurers do not take full advantage of their existing potential and risk missing out on technological advances in customer perception. Research shows that insurers play virtually no role in the online world from the perspective of customers.

- New digital competitors: InsTech start-ups and established tech companies like Google are promoting innovative sales to customers in insurance distribution. With their consistent customer-facing capabilities and strong data analytics capabilities, they pose a serious threat to established insurance distributors in the face of customer access.

- Regulation: Increasing regulation and greater importance of consumer protection require complex, transparent, and comprehensible consultation and sales processes as well as the necessary qualification of sales staff. Traditional business models suffer due to increased process requirements and high costs. The increasing demands will increasingly lead to channel share shifts.

- Demography: The demographic developments cause an aging society, which is also reflected in the customer and intermediary structures.

- Cost pressure: Cost-effectiveness and productivity are the deciding factors. The reduced cost-bearing capacity of the products due to the low interest rates, the regulatory requirements and the decreasing commission income require a higher cost management in sales than is often the case today (Mayers, 1997, p. 69).

The future-oriented design of the sales mix must not only focus on profitability and efficiency. Sales will only be successful in the future if it fully aligns with customer needs.

They expect that they will be able to transfer the positive experiences from other digitally oriented industries to their interactions with insurance companies. Customers are already choosing many different ways of accessing insurers and using the most convenient or effective channel for them (Olins, 1995, p. 44). For example, about half of the customers are informed about their insurance online before signing the contract. Online accounts, however, still account for less than a fifth of new contracts. Unlike in the past, the access route is thus no longer linear.

This changed customer journey is forcing insurers to develop sophisticated and integrated solutions for customer interaction. The customer journey describes the various contact points of a potential customer with the insurance at different points in the sales process.

When designing the future sales structure, the offer of individual customer journeys must therefore be in the foreground. Such a tailor-made customer journey is made possible by three key elements of the sales model of the future: the networking of sales channels and services, the consistent optimization of process and cost 
efficiency, and the corresponding technological support of the sales process (Ettner, 1997, p. 88).

It will be necessary to enter into effective partnerships in the design of the service offering. Distributors can be agencies and brokers as before (Günter, 2001, p. 24).

Furthermore, when planning the model, the question must be clarified as to how future sales success will be defined. In doing so, insurers must determine which key figures can be used to measure and manage the performance of the sales organization (Karten, Nell, Richter, \& Schiller, 2017, p. 22).

- Expanded direct sales, where the communication with the customer either online or via call center runs and is combined with systematic advice, for example by video telephony.

- Ecosystem experts specializing in offering insurance as an integral part of existing or emerging ecosystems (such as smart home systems). This requires building and deepening cross-industry partnerships with other companies.

- Specialists for third-party, broker, and partnership sales, who sells insurance integrated into the (online) offer of other business systems without direct customer contact.

- Digitized exclusivity distribution focused on personal sales, utilizing all the technical possibilities to increase efficiency and providing a strong integration of online and offline.

- Fully integrated multi-channel distribution geared directly to the needs of the hybrid customer, a smooth customer journey, and complete channel integration (Beenken, 2010, p. 80).

\section{Date and Empirical Results}

Effective inventory management is a crucial success factor in sales. Through qualitative and end-to-end processes will be among others.

- Increased the interaction between insurer/distributor and customer;

- Enriched the available information about the customer and thus created the opportunity to make more tailor-made offers;

- Increased customer satisfaction as well;

- Ensured that all regulatory requirements are met.

In summary, this leads to an increase in revenue through cross-/upselling or even an effective cancellation and termination avoidance.

Today, the inventory is usually assigned to individual sales partners and inventory management and inventory management are their sole responsibility. Our analyses and discussions with sales partners as well as sales managers and executives show that the quality of inventory management varies greatly between the individual sales partners and that there is often a considerable need for optimization. This means, on the one hand, that traditional distribution channels do not sufficiently exploit the existing potential. On the other hand, new insTech companies are using such gaps in inventory management to specifically lure customers and stocks. Digitally consolidate the "insurance folder" of the customer and also offer analysis and optimization functions, in effect so the digital replacement of today's insurance broker want to effect. There are other offers on the market, in addition to a complete transparency on commission figures and the repayment of commissions, depending on the interpretation of the commission tax prohibition, or to provide for the donation of parts of the commission.

Central process specifications and controls, data mining, and data analytics as well as digital information provision for distribution partners for targeted inventory processing should be the focus here. 
If we think about inventory management consistently, we also have to ask ourselves whether the current system can simply be "only" optimized - or whether new types of allocation and distribution mechanisms are more effective: for example, the agreement of rules that stipulate that there are insufficient. In extreme cases, it would also be conceivable that all stocks are assigned centrally and all distributors process the stocks according to defined rules and a processing fee for the respective sales or support activity. Possible embodiments are shown in the diagram below.

Optimization of the today's system

- Stock allocation to distribution partners/units (usually according to initial acquisition).

- Determining or agreeing on and keeping to exhaustion/targeting objectives in the event of non-attainment of sanctions if necessary.

- In the case of initiation of interaction by customers, no grandfathering protection, to determine appropriate remuneration compensation.

- Change in the handling of stock assignment.

- Central management of unsecured stocks.

- Create capacities for central inventory management.

- Customer assignment to be acquired first of all as a sales partner/unit.

- Determining or agreeing on and keeping to exhaustion/targeting objectives in case of non-achievement, if necessary, removal of the relevant part of the stock.

- Definition of clear rules for the acquisition in foreign unattended holdings.

- Creation of central inventory management.

- Build capacity for central inventory management and centralized management of all stocks.

- Allocation of acquisition or exploitation activities to Distributor Units.

- Compensation of individual activities or individual, incremental sales successes.

\section{Conclusion}

Sales models are complex, interlocking systems. Therefore, it is important to look at all elements of the sales model and to look in detail at what changes are needed to reorient the strategy. You can divide these elements into eight categories. Six of these categories are already present in one form or another in today's distribution models and need to be revised or supplemented accordingly. For two other categories (partnerships/participations and technology), insurers generally need to specifically build up new capabilities to meet the demands of sustainable distribution models (Dixon, 2011, p. 23).

In order not to overburden the organization, it is important that insurers organize the design and change of each element step by step, because the biggest challenges in building a new sales model lie in the networking of the individual elements, the control of interactions, and a meaningful sequential implementation.

Although many insurers are aware of the strong pressure for change, industry-typical hurdles often prevent the consistent realignment of traditional sales models. The biggest hurdles are:

- High complexity of sales and networking of the individual elements of the sales model and the associated risk of unwanted side effects;

- Fears of increasing customer dissatisfaction due to friction loss in processes and loss of sales partner motivation;

- Fear of the vicious circle of loss of distribution resources and the associated decline in business; 
- Lack of resources and skills to successfully exploit technological change opportunities, such as data analytics or lead generation;

- Restrictions in the technical infrastructure or bottlenecks in IT adaptation;

- High utilization of the management with challenges in the daily business-therefore neglecting the long-term orientation.

The combination of great need for change and the presence of these hurdles put increasing pressure on insurers to start thinking about realigning their distribution (Hilker, 2017, p. 22).

Insurance companies have already made targeted changes in recent years. However, due to the further increase in pressure for change, a fundamental redesign of the current sales models is to be expected.

The basis of the transformation process should be an individually determined strategic objective and the corresponding implementation path. Both have to be shared by the sales management and the entire board. As soon as there is clarity about the strategy, the necessary operational changes can be aligned with it and defined with the necessary depth of detail.

The author advises on numerous insurance policies in the area of distribution and reorientation. We recommend a multi-stage process that systematizes this process, specifically avoids the hurdles described above and ensures sustainable results.

\section{References}

Beenken, M. (2010). Vertriebsmanagement: Fach- und Führungskompetenz für die Assekuranz. Köln: Versicherungsverlag. Browne, M. J., \& Kim, K. (1993). An international analysis of life insurance demand. The Journal of Risk and Insurance, 60(4), 616-634.

Dixon, M., \& Adamson, B. (2011). The Challenger Sale: Kunden herausfordern und erfolgreich überzeugen. München: Redline Verlag.

Ettner, S. L. (1997). Adverse selection and the purchase of medigap insurance by the elderly. Journal of Health Economics, 16(5), 543-562.

Gunter, B. (2001). Kundenwert: Grundlagen-Innovative Konzepte-Praktische Umsetzungen. Frankfurt: Springer Verlag.

Hilker, C. (2017). Social-Media-Marketing am Beispiel der Versicherungsbranche: Dissertation. Norderstedt: Books on Demand.

Karten, W., Nell, M., Richter, A., \& Schiller, J. (2017). Einführung: Grundlagen der Versicherungsmärkte. Wiesbaden: Springer Fachmedien Wiesbaden.

Mayers, D. (1997). Guaranty funds and risk-taking evidence from the insurance industry. Journal of Financial Economics, 44(1), 3-24.

Olins, W. (1995). The new guide to identity: How to create and sustain change through managing. Frankfurt: Springer Verlag.

Sommer, D. W. (1996). The impact of firm risk on property-liability insurance prices. The Journal of Risk and Insurance, 63(3), 501-514. 